I. Will the position of the profession, socially and financially, be improved as a whole? I think that it will. If I thought that provident dispensaries were for the advantage of a portion, and not the whole profession, I would cease to support them. Provident dispensaries are intended for the classes above pauperism and below competency to pay for medical advice at the usual charges; i. $e$., they include as members the class at present drawing on the gratuitous medical aid of the hospitals, and the class which is attended by private practitioners for very small fees. Now every one will recognise that, if the large numbers which I gave of those who are in receipt of gratuitous medical aid be approximately correct, a small payment from each would make a large addition to the income of the profession as a whole. And then, as to those who pay very small fees, it has often surprised me to hear from general practitioners working amongst the poor how much they lose by bad debts. It is no unusual thing to meet with gentlemen who calmly submit to an annual loss of 25 per cent. of booked accounts; and this loss is greatly caused by those who should belong to provident dispensaries. In proof of this I can refer to two practitioners near the Haverstock Hill Dispensary, who tell me that their percentage of bad debts has been diminished from 20 to $\mathbf{2} 2$ per cent. since the dispensary commenced. They can now advise their poor patients to join the dispensary. The work of visiting the poor who pay, or rather who pretend to pay, must be done at a great waste of strength to the practitioner, whereas in the provident dispensary the patients are subject to fixed rules. They can be made to attend on certain days ; and, if visits at home be made, they are applied for early in the day. In addition to this, the practitioner, instead of having the trouble of making oat bills which may never be paid, obtains a certain fixed remuneration in proportion to the work done. To give two instances : medical officers generally attend twice a week for an hour; and, in addition, they see patients at their homes if necessary. Thus, at Haverstock Hill, the average daily number of visits for each medical officer is four, and the average annual remuneration is $£ 90$. At Northampton, the average daily number of visits varies from twenty-six to thirty, and the remuneration is $£ 500$; and so on. These visits are easily made in the usual rounds of practice. At some dispensaries, it is complained that the medical officers entrust the seeing of their patients to assistants ; and that they thus keep up a monopoly which is unfair to the other medical practitioners of the town. It is with the view of preventing this, and of including as many of the practitioners of each district as possible, that the Medical Committee of the Charitable Organisation Society have proposed that about $\mathbf{1}, 500$ members should be allowed to each doctor; and they even hope that, when these institutions become self-supporting-i. $e$., when the real liability of members can be ascertained and paid for-it will be possible to include all the resident practitioners who are willing to do the work.

The rule for preventing unsuitable admissions is worthy of note. The patient, if he be in good health, enters his name, but does not become a member for a month, during which inquiries can be made. Still abuses creep into these, as into every other institution. Thus patients enter, pre'ending to be healthy, and at the end of their month of probation they declare a chronic malady. These, however, are the exceptions. I prefer rather to think of the many who pay on month after month and year after year without requiring aid; and I like to quote the experience of myself and others, who have almost invariably found the provident dispensary patient less exacting of his doctor, and more thoughtful and grateful for attention, than the charitable dispensary patient.

2. What advantages have the patients? They may be shortly enumerated thus. They make their payments in time of health, and are attended by men whose interest it is to keep them well. Their medical antecedents are known, as they are always attached to the same institution, and attended by the same medical officer. There is no delay in obtaining letters; and thus the patient is saved the danger of no treatment, and of counter-practice, which is worse. I heard it lately given as an objection to provident dispensaries by a working man at a public meeting, that the physicians and surgeons who attend in hospital out-patient rooms do not attend at provident dispensaries. There is some force in this ; and it was with the view of obtaining the services of that class of the profession, as well as providing a substitute for out-patient departments, that the Charity Organisation Society specially recommended the affiliation of the provident dispensaries to the hospitals.

3. The third and last point on which I shall say a few words is, To what extent might the science of medicine be advanced ? First, by increased facilities for medical teaching. This provident system might replace the apprenticeships of the past, in giving the student practical tact. He might thus see disease at its commencement in the dispensary, and follow it through its course in the hospital to its termination, under suitable guidance. Secondly, as a machinery for register- ing disease, nothing could be better than the provident system. Diseases are seen early, and can be easily followed up. Thus both timely warning would be given of epidemics by weekly returns, and yearly reports could be based upon these. Forms with this view have been drawn up by the Medical Subcommittee of the Charity Organisation Society, and approved by Dr. Farr; and I would respectfully suggest that that scheme for the registration of sickness be considered, and, if it be worthy of the honour, endorsed by some body of position, such as the Council of this Branch.

And now, gentlemen, I have finished the short summary to which I am limited. In any case, I should consider it unnecessary to enter into fuller details, as I explained the working of provident dispensaries in a paper read before this Branch two years ago. Since that time, the profession has been coming round to approve of provident dispensaries; and the most recent action taken was the conference of December in these rooms, called by the Charity Organisation Society for the consideration of its report and rules for provident dispensaries. Knowing as I do how carefully those rules were prepared, modified as they are by the advice of the best authorities on this subject, I have every confidence in recommending them as a groundwork at least to all who think of commencing provident dispensaries.

\section{NOTES FROM OPHTHALMIC PRACTICE.}

BY JAMES DIXON, F.R.C.S.

Consulting Surgeon to the Royal London Ophthalmic Hospital.

\section{III-Malignayt Deposit iv Eveball.}

THE two following cases are brought forward, not as in themselves offering any unusual form of disease, but as well illustrating the value of the ophthalmoscope in revealing the existence of malignant growth, while as yet unattended by any trace of inflammation in the external tissues. Indeed, in the former of these cases, the defect of sight was so entirely uncomplicated with other symptoms in the eye, that the patient herself believed it to be simply the result of some derangement of stomach. I have already published a note of this case, but I now reproduce it as a suitable companion to the succeeding one, and as having acquired more interest from the condition of the patient, after a period of fourteen years, having been ascertained. She is now (February 1872) in good health, and has had no symptoms of any visceral disease since the operation.

CASE I. - A young lady, aged 26 , consulted me, May 3 Ist, I 858 , for defective sight in the left eye. Four months previously she had noticed that objects in certain positions were not seen with this eye while objects in other positions were seen almost perfectly. The right eye was quite unaffected, and she attributed the defect in the other to some form of indigestion. There was no trace of inflammation. The only point in which the affected eye differed from the sound one was that, on careful inspection, the iris could be observed to bulge very slightly forwards at its lower part, and this caused the pupil to deviate, in a very trifling degree, from the circular form. In all other respects the iris seemed perfectly healthy. Objects placed above the level of the eye were not seen, but those below that level were seen almost as well as with the sound eye, and even small type could be read, when the page was held in such a position as to allow the rays from it to fall upon the upper part of the retina. When the pupil had been dilated with atropine, I could see a rounded greyish mass, of considerable size, rising up from the floor of the vitreous chamber. In consequence of the transparency of the media, this mass was beautifully seen with the ophthalmoscope. The upper part of the retina seemed healthy. I removed the globe on the roth June, 1858 .

From the lower part of the vitreous chamber a rounded mass, about the size of a small hazel-nut, rose up nearly as high as the middle of the lens. The base of the tumour adhered firmly to the sclerotic ; and the choroid, which had been detached from its position, was, for some distance, expanded over the sides of the tumour, becoming gradually thinned, and finally lost, some distance below the summit. The retina had been gradually raised up by the mass, but did not appear to be changed in structure. The lens and vitreous body were transparent. The tumour presented all the microscopic character of cancer-tissue ; being chiefly made up of transparent tubes, with granular excrescences; tubes containing elongated nucleated cells; and free rounded cells of various sizes.

CASE II.-Mr. B., aged 59, consulted me, May 3 rd, I87r. Iis left eye was good, though myopic. The right, he said, had been failing for the last two years. The only defect visible, on cursory observation, was a slight sluggishness of the pupil. The field of vision was very limited. 
Two fingers in contact held up before him, a little towards his right hand, were recognised; but when they were placed only three inches apart, one alone was visible. The four corners of a sheet of notepaper could not be seen at the same time. He could barely read a few letters of No. I 8 (Jæger). After applying atropine, I used the ophthalmoscope. The cornea and the lens were perfectly clear, but the vitreous body was slightly cloudy, and I could not see the optic nerve. When the eye was adducted, an abruptly defined black shadow filled the outer portion of the pupillary area, evidently the effect of some large mass behind the lens intercepting the rays of light coming from the fundus. Concentrated direct light brought into view a considerable bulging of the retina at the outer side of the globe, forming a rounded mass, projecting into the vitreous humour to such an extent as to hide the optic nerve. What was the nature of this projection? The length of timetwo years-during which sight had been failing, the total absence of pain, and of every trace of inflammation, pointed, I thought, to harm. less deposit, or serous effusion beneath the retina, rather than to malignant disease. I begged the patient, however, to see me again in the event of either inflammation or pain setting in.

On the Ist of December he returned, with a striking change in the eye. The globe was hard; the superficial veins were large and distended; and there seemed to be a slight bulging of the scerotic at its outer part. The cornea was still clear; the pupil dilated and fixed ; the lens quite opaque. There was bare perception of strong light. I had now no doubt of the deposit being malignant, and urged immediate operation. The eye was removed on Decem! ber $g^{\text {th }}$. From the upper and outer part of the choroid a rounded tumour projected into the vitreous humour, its base reaching to within a quarter of an inch of the optic nerve, while, in front, it extended into the ciliary body, and only just stopped short of the surface of the lens. The retina, much thinned, was continuous over the sufface of the tumour. Its tissue was dark brown, and very vascular, and was made up of well-formed narrow spindlecells, and of other cells, rounded or oval, of various sizes, intermixed with rounded and irregular pigment-masses which gave the brown colour to the tumour. The optic nerve, at its cut surface, seemed slightly pigmented; but this appearance was really due to numerous scattered blood-crystals and not to pigmented cells.

\section{ELECTROLYSIS AND THE GALVANIC CAUTERY. BY JULIUS ALTHALS, M.D.}

In the JouRnal for February Ioth, I872, Mr. Callender has published notes of a clinical lecture on some surgical cases in which the continuous electric current was used; and as some confusion of terms occurs repeatedly in that paper, I beg to offer a few remarks on it, with a view to correction. In the first instance, Mr. Callender says that he has used two kinds of operation; viz., a mild current, applied either by means of ordinary charcoal electrodes, or by means of two or more needles-serres fincs; and secondly, a more powerful current, so as to cause actual burning of the tissues. The first operation is, according to him, that of electrolysis ; the second, that of the galvanic cautery. $\mathrm{He}$ concludes from his experience that electrolysis is not worth much, but that he will continue to give it a further trial, although he cannot feel sanguine as to the results; while, with regard to the cauterising effects of the continuous current, he admits that we have a powerful and valuable remedy, more especially for the removal of recurrent masses which spring up about the scar-tissue after removal of a cancer, and which, if allowed to increase, necessitate for their removal a considerable operation.

4 In the successful cases which he relates, Mr. Callender has not used the "galvanic cautery" at all, but only electrolysis. The fundamental difference between the galvanic cautery and electrolysis is, that the former effects our purpose simply by heat, and the latter chiefly, although not exclusively, by chemical action. In using the cautery, we render a platinum.wire incandescent by the calorific action of a few large pairs of Grove's or Bunsen's battery, charged generally with nitric acid, in order to diminish as much as possible the essential resistance of the battery. According to the more or less intense action of such a battery, we may, ad libitum, produce red or white heat in the platinum-wire, and the heat thus produced differs in no way from that of the ordinary actual cautery. The galvanic has, however, this advantage over the actual cautery, that the supply of heat from the former is more continuous than from the latter, so that it is preferable for prolonged operations. Moreover, it may be made to act upon deeply seated structures which are inaccessible to the knife or to the actual cau tery, because the galvanic cautery may be introduced while cold, and may be put into action when it is in its proper place.
The action of electrolysis, on the other hand, is chiefly chemical, and the effects produced are, in accordance with physical laws, the more thorough and energetic, the larger the number of the plates of the battery which are utilised. This is the reason why Mr. Callender has been more or less unsuccessful with a "mild current" (which he calls " electrolysis"), and successful with a powerful current (which he calls the "galvanic cautery"). The chief result of his experience is, therefore, the same as that of the other observers ; viz., that in many forms of tumours a powerful current must be used in order to insure their destruction, and that a mild current produces only slight effects. Dr. Ehrenstein of Dresden has ccmpletely removed a fibroid tumour, similar to the one described by Mr. Callender, by somewhat more powerful and prolonged applications.

The needles which are used in electrolytic operations are repeatedly called serres finc's in Mr. Callender's paper, evidently from a clerical error. The needles are not serres finc's, but their heads are connected by means of a scrres fines conductor with the negative conducting wire of the battery. (Vide my Treatise on Medical Electricity, p. 54I.)

To those who are interested in this subject, I beg to recommend the perusal of a little brochuce on Electro-Surgery, by Dr. Hugh Campbell (Alexander, Old Cavendish Street), which has recently been published, and in which considerable evidence in favour of the electrolytic treatment is brought forward.

\section{CLINICAL MEMORANDA.}

\section{TREATMENT OF ENURESIS.}

CASES of enuresis are, as a rule, very troublesome to deal with; and, therefore, though I have nothing new to recommend, I think it may be worth while to record a very successful case.

Emily B., $\sigma_{2}^{1}$ years, healthy, and of healthy parents, had from infancy up till November last, been used to wet the bed nightly. All sorts of treatment had been tried in vain. I ordered the lower part of the spine to be sponged nightly before she was put to bed. This has been continued ever since, and she has only once wet the bed. This speaks for itself. I shall continue the treatment for some months longer, and have no doubt a permanent cure will have been effected. George H. Savage, M.D., Alston, Cumberland.

\section{THERAPEUTIC MEMORANDA.}

\section{TREATMENT OF TUMOURS BY THE CONTINUOUS ELECTRIC CURRENT.}

IN the BRITISH MEDICAL JOURNAL of February Ioth, are some interesting clinical notes on this subject by Mr. Callender, which have suggested my recording the following case of recurrent fibroid tumour and the results of the electrolytic treatment.

The patient, a young woman, had two years before I saw her a large tumour occupying the infraspinous portion of the scapula, which was at that time removed in the Belfast General Hospital by Dr. Murney, and found to be recurrent fibroid. Its reappearance commenced above the scapular spine, gradually spreading until a large mass filled the supraclavicular space, pressing and involving all the important structures, and slowly advancing with fatal grasp on the trachea. In order to stay or divert this threatening extension of the tumour, I tried electrolysis. The battery used was Smee's, with six cells. Into the substance of the most accessible portion, and close to the trachea, I introduced two negative and two positive needles. The continuous current was thus applied for a quarter of an hour, sometimes longer, three or four times a week for a month, with the following result. The part of the tumour acted on had certainly paused in its progress, and even diminished in its size, but the surrounding portions had as decidedly assumed a more rapid growth. The treatment was of course discontinued, as it had really done more harm than good, and by acting as a stimulant seemed to hasten the inevitable strangulation, which took place with great suffering two months afterwards.

This was a case in which it was hopeless to expect much benefit to accrue from the action of the continuous electric current; and though it confirms the value of the treatment when only small tumours are to be dealt with, yet it shows that it cannot be used indiscriminately, as its partial application to some large tumours is by no means free from mischief. J. Sinclair Holden, M.D. Physician to Larne Union Hospital. 